\title{
Superficial Shoulder Muscle Synergy Analysis in Facioscapulohumeral Dystrophy During Humeral Elevation Tasks
}

Citation for published version (APA):

Essers, J. M. N., Peters, A., Meijer, K., Peters, K., \& Murgia, A. (2019). Superficial Shoulder Muscle Synergy Analysis in Facioscapulohumeral Dystrophy During Humeral Elevation Tasks. leee Transactions on Neural Systems and Rehabilitation Engineering, 27(8), 1556-1565. https://doi.org/10.1109/TNSRE.2019.2927765

Document status and date:

Published: 01/08/2019

DOI:

10.1109/TNSRE.2019.2927765

Document Version:

Publisher's PDF, also known as Version of record

Document license:

Taverne

Please check the document version of this publication:

- A submitted manuscript is the version of the article upon submission and before peer-review. There can be important differences between the submitted version and the official published version of record.

People interested in the research are advised to contact the author for the final version of the publication, or visit the DOI to the publisher's website.

- The final author version and the galley proof are versions of the publication after peer review.

- The final published version features the final layout of the paper including the volume, issue and page numbers.

Link to publication

\footnotetext{
General rights rights.

- You may freely distribute the URL identifying the publication in the public portal. please follow below link for the End User Agreement:

www.umlib.nl/taverne-license

Take down policy

If you believe that this document breaches copyright please contact us at:

repository@maastrichtuniversity.nl

providing details and we will investigate your claim.
}

Copyright and moral rights for the publications made accessible in the public portal are retained by the authors and/or other copyright owners and it is a condition of accessing publications that users recognise and abide by the legal requirements associated with these

- Users may download and print one copy of any publication from the public portal for the purpose of private study or research.

- You may not further distribute the material or use it for any profit-making activity or commercial gain

If the publication is distributed under the terms of Article $25 \mathrm{fa}$ of the Dutch Copyright Act, indicated by the "Taverne" license above, 


\title{
Superficial Shoulder Muscle Synergy Analysis in Facioscapulohumeral Dystrophy During Humeral Elevation Tasks
}

\author{
Johannes Maria Nicolaas Essers ${ }^{\circledR}$, Anneliek Peters, Kenneth Meijer, \\ Koen Peters, and Alessio Murgia ${ }^{\circledR}$, Member, IEEE
}

\begin{abstract}
Facioscapulohumeral dystrophy (FSHD) is a progressive muscle-wasting disease which leads to a decline in upper extremity functionality. Although the scapulohumeral joint's stability and functionality are affected, evidence on the synergetic control of the shoulder muscles in FSHD individuals is still lacking. The aim of this paper is to understand the neuromuscular changes in shoulder muscle control in people with FSHD. Upper arm kinematics and electromyograms (EMG) of eight upper extremity muscles were recorded during shoulder abduction-adduction and flexion-extension tasks in eleven participants with FSHD and 11 healthy participants. Normalized muscle activities were extracted from EMG signals. Non-negative matrix factorization was used to compute muscle synergies. Maximum muscle activities were compared using non-parametric analysis of variance. Similarities between synergies were also calculated using correlation. The Biceps Brachii was significantly more active in the FSHD group (25 $\pm 2 \%$ ) while Trapezius Ascendens and Serratus Anterior were less active ( $32 \pm 7 \%$ and $39 \pm 4 \%$, respectively). Muscle synergy weights were altered in FSHD individuals and showed greater diversity while controls mostly used one synergy for both tasks. The decreased activity by selected scapula rotator muscles and muscle synergy weight alterations show that neuromuscular control of the scapulohumeral joint is less consistent in people with FSHD compared to healthy participants. Assessments of muscle coordination strategies can be used to evaluate motor output variability and assist in management of the disease.
\end{abstract}

Index Terms-FSHD, humeral elevation, motor control, muscular dystrophy, muscle synergies, scapula rotation.

\section{INTRODUCTION}

$\mathbf{F}$ ACIOSCAPULOHUMERAL Dystrophy (FSHD) is characterized by progressive muscle wasting which primarily affects the face and shoulder area [1], [2]. Muscle quality

Manuscript received December 21, 2018; revised June 13, 2019; accepted July 7,2019 . This work is part of the research programme Symbionics Perspectief Program with project number 13523, which is (partly) financed by the Netherlands Organisation for Scientific Research (NWO). (Corresponding author: Johannes Maria Nicolaas Essers.)

J. M. N. Essers and K. Meijer are with the Maastricht University Medical Centre+, Department of Nutrition and Movement Sciences, 6229 Maastricht, The Netherlands (e-mail: hans.essers@maastrichtuniversity.nl).

A. Peters, K. Peters, and A. Murgia are with the University Medical Center Groningen, Center for Human Movement Sciences, University of Groningen, 9713 Groningen, The Netherlands.

Digital Object Identifier 10.1109/TNSRE.2019.2927765 decreases due to fat infiltration, but is weakly correlated with age where age onset varies greatly [2], [3]. Commonly occurring body impairments and functional limitations include scapular winging, joint instability, and a decline in upper extremity functionality [4]-[8]. In a questionnaire-based survey, reaching and lifting objects above shoulder level were reported as "most limited" activities by $45 \%$ of FSHD participants [6]. Relative surface area, as a measure of the reachable workspace, decreases by 23 to $87 \%$ depending on the level of strength loss, in people with FSHD [9], [10]. Muscles attaching to the scapula are the most affected, with the Trapezius and Serratus Anterior muscles becoming atrophied and showing fat infiltration in more than $85 \%$ of individuals with FSHD [11]. These losses in tissue quantity and quality become evident at the earliest stages of the disease [11], [12] and translate into a diminished strength of the scapular rotator muscles. In turn, this limited muscle function could result in incomplete rotation and stabilization of the scapula.

Electromyographic assessments of muscle function can provide insight in the muscle activation strategies used for scapular stabilization and mobilization in people with FSHD. Previous research has shown an approximately twice as high muscle activity in FSHD participants compared to healthy individuals for the Deltoid, Trapezius Descendens, and synergist Biceps muscles during reaching tasks [13]. The increased activity of selected shoulder muscles can be postulated to compensate for the loss of strength, with scapular mobilization possibly affected as a result. In healthy individuals, scapular mobilization and stability are necessary during humeral elevation, particularly above shoulder level [14]-[16]. At present however, the way in which scapular rotator and humeral elevator muscles are coordinated by FSHD individuals during daily tasks is still unclear. The extent of these alterations that are known to occur in other diseases affecting the shoulder, including stroke, multiple sclerosis, and shoulder impingement [17]-[22], indicate that the neuromuscular output can be affected by the disease.

Muscle synergy analysis can be used to reveal alterations in the coordination of groups of muscles. In healthy individuals the central nervous system activates muscles in groups, as a neural strategy to simplify the control of multiple degrees of freedom [23]. These group activations, commonly called 
muscle synergies, can be described by the relative contribution of each muscle (weights) during a common time-dependent activation command (coefficients) [24]. Muscle synergy analysis of the upper extremity in people post-stroke has revealed alterations in the shoulder muscle synergies during isometric force generation [25] and dynamic tasks [26]. A high similarity between affected and unaffected arm muscle synergies was shown in a variety of daily activities, together with the presence of compensatory strategies by Trapezius and Pectoralis muscles during reaching tasks [25], [27], [28]. In people with FSHD, however, it is unknown how muscle synergies change during the execution of upper extremity daily tasks. Understanding the neuromuscular output can help reveal how the disease-resulting changes in kinematics are underlined by muscular changes, with implications for the long-term management of the condition.

This study concentrates on planar humeral elevation tasks to understand the neuromuscular changes affecting the shoulder muscles, including muscles responsible for scapula rotation and stabilization, in people with FSHD compared to healthy individuals. We hypothesized that in people with FSHD the maximum activity of prime movers of humerus and scapula and of synergist muscles would be higher compared to healthy individuals. Secondly, we also hypothesized that muscle synergies would show alterations in people with FSHD, reflecting the increase in maximum activity, mainly in synergy weights. The second hypothesis was tested to investigate whether the known shoulder mobility limitations in people with FSHD would affect the muscle synergies.

\section{Methods}

\section{A. Participants}

Eleven healthy control participants $(5 \mathrm{M} / 6 \mathrm{~F}, 55 \pm 14 \mathrm{ys}$, $175 \pm 7 \mathrm{~cm}, 69 \pm 8 \mathrm{~kg}, 11$ Right-Dominant (RD)) and eleven participants with FSHD $(6 \mathrm{M} / 5 \mathrm{~F}, 54 \pm 15 \mathrm{ys}, 177 \pm 11 \mathrm{~cm}, 78 \pm 21 \mathrm{~kg}$, 2LD/9RD) were included in this study. Healthy participants were informed by advertisement flyers located at University Medical Center Groningen. People with FSHD were informed about the study through the Dutch Association for Neuromuscular Diseases (Spierziekten Nederland, Baarn, NL). Healthy and participants with FSHD were included in this study if they were aged between 18-75 years, able to read and understand Dutch, and able to give written informed consent. Additional criteria for people with FSHD were the ability to transfer from wheelchair to chair with side- and lower back-rest, and a Brooke scale score of 3 or 4 . Healthy participants were excluded if they were diagnosed with pathologies that could interfere with the measurement results, had a presence of pain in the shoulder, a history of severe trauma of the shoulder within the previous two years (e.g. fracture, luxation). Participants with FSHD were excluded if they had comorbidities that could interfere with the measurement results, previous surgery on the right shoulder, extrinsic causes of shoulder pain, a history of severe trauma, or were unable to elevate the right arm above $30^{\circ}$. Age, gender, hand-dominance, body height, and body mass were also recorded. The central Medical Ethical Committee of University Medical Center Groningen

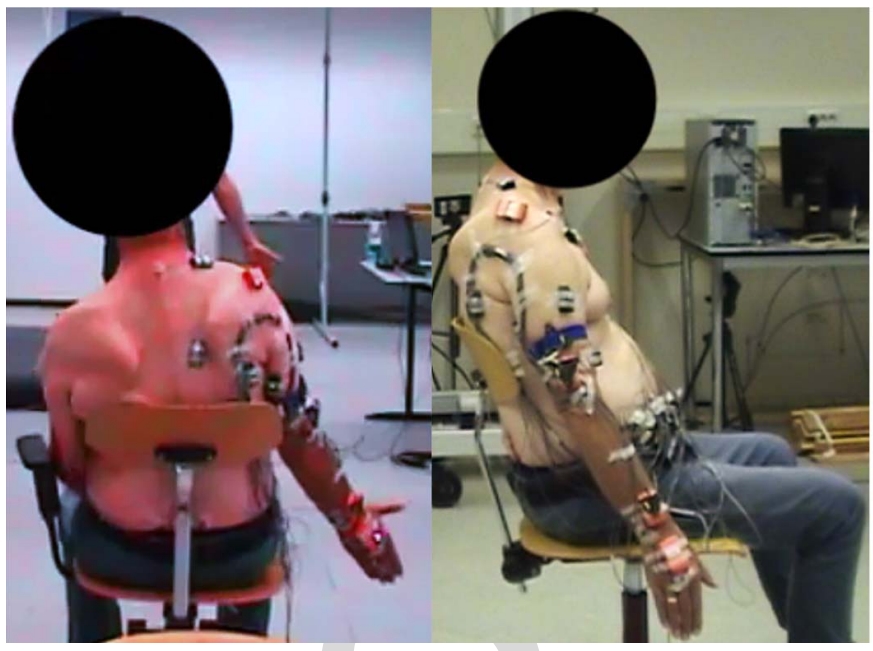

Fig. 1. Experimental set up of a FSHD participant about to perform shoulder abduction-adduction (left) and flexion-extension (right).

approved the study (NL55711.042.15), which was carried out in accordance with the guidelines of the Helsinki protocol. Participants were informed about the procedure beforehand and provided written informed consent.

\section{B. Movement Tasks}

The participants were positioned in a chair with a left side-rest and lower back-rest and with the seat height adjusted to achieve a knee flexion angle of $90^{\circ}$. Participants received detailed instructions prior to the execution of each task regarding the movement. For the shoulder abduction-adduction task (SAA), the right arm was first positioned downward with the elbow straight and the hand palm facing forward (Fig. 1). The movement consisted of lifting the arm as far as possible in the coronal plane and bringing it back to the start position while keeping the trunk and elbow straight, with the hand palm facing forward. The shoulder flexion-extension task (SFE) was similarly executed but with the hand palm facing medially and the thumb pointing forward. One researcher mirrored each task at pace with the participant. Each task was repeated three times but not consecutively as the order of the tasks was randomized.

\section{Measurement and Processing}

Kinematics of the trunk, chest, and right-sided upper extremity was recorded using the Optotrak 3020 system (Northern Digital Inc., Canada) [29]. Single markers were placed on bone landmarks and rigid bodies were placed on soft tissues on the lateral side of the upper and lower arm as shown in table 1. Humeral elevation was calculated from the recorded kinematics and expressed as joint angle between trunk and humerus where $0^{\circ}$ represents the arm straight downward and $180^{\circ}$ straight upward.

Surface electromyograms (EMG) of the right side muscles were recorded for the prime humeral elevator/depressors and scapular rotator muscles, i.e. medial Deltoid, Pectoralis Major clavicular head, Latissimus Dorsi, Trapezius Descendens, Trapezius Ascendens, and Serratus Anterior 5-6th rib, and 
TABLE I

SINGLE AND RIGID BOdY MARKERS

\begin{tabular}{cl}
\hline \hline Marker \# & Body location \\
\hline 1 & Spinal process of 7th cervical vertebra \\
2 & Jugular notch clavicle-sternum \\
3 & Xiphoid process of sternum \\
4 & Acromio-clavicular joint (left) \\
5 & Acromio-clavicular joint (right) \\
$6-8^{*}$ & Lateral upper arm (right, 1/3 of acromion to lateral epicondyle) \\
9 & Lateral epicondyle (right) \\
10 & Medial epicondyle (right) \\
$11-13^{*}$ & Lateral lower arm (right, 1/2 of lateral epicondyle to styloid \\
& process of radius) \\
14 & Styloid process of radius (right) \\
15 & Styloid process of ulna (right) \\
16 & Head of the 3rd metacarpal (right) \\
\hline \hline
\end{tabular}

Rigid body refers to a rigid cluster of three markers.

the synergist muscles Biceps Brachii short head and Triceps Brachii long head. Data were captured at $2000 \mathrm{~Hz}$ using the Delsys Trigno system (Delsys Inc., UK) [30]. Maximum voluntary contractions (MVCs) were recorded beforehand (appendix, table 2). The recorded EMG data were filtered with a 4th order Butterworth $20-450 \mathrm{~Hz}$ bandpass and a $49-51 \mathrm{~Hz}$ bandstop filter, rectified, smoothened with a $100 \mathrm{~ms}$ moving window, normalized to the maximum amplitudes derived from all MVC and task recordings, and filtered with a 4th order Butterworth $5 \mathrm{~Hz}$ low pass filter. The maximum task-specific muscle activity was extracted as highest normalized amplitude over all task repetitions. Time was normalized to 1001 samples for each repetition ranging from 0 to $100 \%$.

Kinematics and EMG recordings were executed consistently with one researcher placing the markers and electrodes and another research assessing the placement and data quality.

\section{Muscle Synergy Extraction}

EMG data were pooled per participant to contain equal samples of both tasks in a single matrix to investigate the shared synergies across humeral elevation planes. Muscle synergies were then extracted using Non-Negative Matrix Factorization (NNMF), which decomposed the matrix into 1 to 8 sets of components consisting of weights and coefficients [24]. These weights and coefficients were converted to a unit vector and represent normalized muscle activity (0-1). Additionally, for each set of components (synergy), the NNMF provided the percentage of variance accounted for of all muscles (VAF) and per individual muscle (VAFM). The minimum required number of synergies per participant were extracted using as thresholds VAF $>90 \%$ and VAFM $>75 \%$ [24]. The variance accounted for per task was calculated with respect to the reconstructed data (weights * coefficients) for each synergy. Coefficients were then averaged for pooled repetitions per task. Synergies were clustered within each group using an iterative process that matched weights in an ascending order based on Pearson's correlation coefficients.

The muscle synergy extraction procedure was executed for two conditions. One condition included the complete motion and the second condition focused on the upward motion up to $60^{\circ}$ humeral elevation.

\section{E. Statistical Analysis}

Humeral elevation differences between groups were investigated using independent-samples Mann-Whitney $\mathrm{U}$ tests. To test the first hypothesis on whether EMG amplitudes of prime movers and synergist muscles would be higher in people with FSHD, the maximum muscle activities were compared using a non-parametric analysis of variance, with Task and Muscle as within-group factors and Group as between-group factor ( $\mathrm{R}$ v3.5.0, The R Foundation for Statistical Computing, nparLD package) [31]. The Post-hoc tests were performed accordingly between groups using independentsamples Mann-Whitney $\mathrm{U}$ tests, and between tasks using related-samples Wilcoxon signed rank tests. Alpha levels were corrected for multiple comparisons and set at 0.025 . Effect sizes were expressed as Cohen's d (very small: 0.00- 0.01, small: $0.01-0.20$, medium: $0.20-0.50$, large: $0.50-0.80$, very large: $0.80-1.20$, and huge: >1.20) [32]. Furthermore, the standard error of measurement (SEM) was calculated on the consistency of maximum muscle activity over repetitions for each group and consequently used to calculate standard deviations of mean group differences [33].

To test the second hypothesis on whether muscle synergies were altered or dissimilar in people with FSHD, Pearson's correlation coefficients were used to quantify synergy weight and zero-lag correlation coefficients to quantify synergy coefficient similarities $(\alpha: 0.025)$ [34]. Correlation coefficients values were calculated only for significantly similar synergy weights to minimize type I errors. Additionally, within-group similarity was calculated through the EMG cross-validation method [35], and Pearson correlations for synergy weights only. Differences in within-group similarity from EMG cross-validations were tested with Fisher's least significant difference (LSD) post-hoc test with the number of muscle synergies as a factor $(\alpha: 0.025)$.

\section{Results}

\section{A. Kinematics}

All participants successfully completed all tasks. The control group elevated the humerus significantly higher in SAA to $149 \pm 19^{\circ}(N=22$, Cohen's $d: 4.28, p<0.001)$ and in SFE to $141 \pm 17^{\circ}(N=22$, Cohen's $d: 3.09, p<0.001)$. The FSHD group's maximum humeral elevation was $70 \pm 18^{\circ}$ and $83 \pm 20^{\circ}$ during the SAA and SFE task, respectively.

\section{B. Muscle Activity}

Maximum muscle activities were significantly different for Task $(\mathrm{p}<0.010)$, Muscle $(\mathrm{p}<0.001)$, Muscle*Task $(\mathrm{p}<$ $0.001)$, Group*Muscle $(\mathrm{p}<0.001)$, and Group*Muscle*Task ( $\mathrm{p}<0.001)$, but not for Group (p:0.248) or Group*Task (p: 0.121). Post-hoc tests of the Group*Muscle*Task interaction effect revealed that maximum muscle activities were significantly different between groups (FSHD-control) for Biceps Brachii SFE: $+25 \pm 2 \%(N=22$, Cohen's $d: 1.38 p: 0.013)$, Trapezius Ascendens SAA: $-32 \pm 8 \%(N=22$, Cohen's $d$ : 

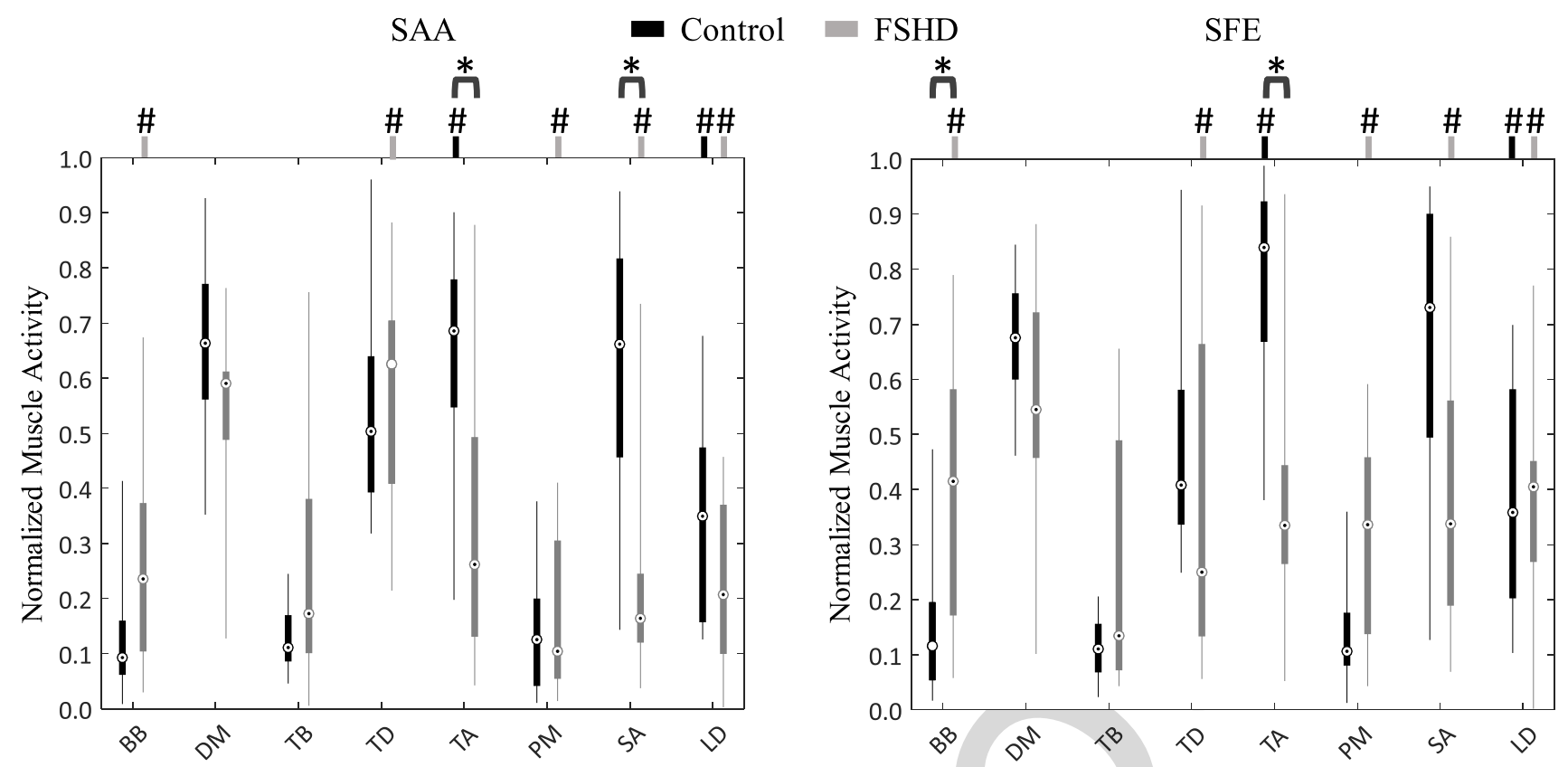

Fig. 2. Boxplots of maximum muscle activity amplitudes of control (black) and FSHD group (grey) for the SAA (left) and SFE (right) tasks (*: significant group differences; \#: task differences; $p<0.025)$. Boxes and whiskers indicate minimum, first quartile, median, third quartile, and maximum. BB: Biceps Brachii; DM: medial Deltoid; TB: Triceps Brachii; TD: Trapezius Descendens; TA: Trapezius Ascendens; PM: Pectoralis Major; SA: Serratus Anterior; LD: Latissimus Dorsi.

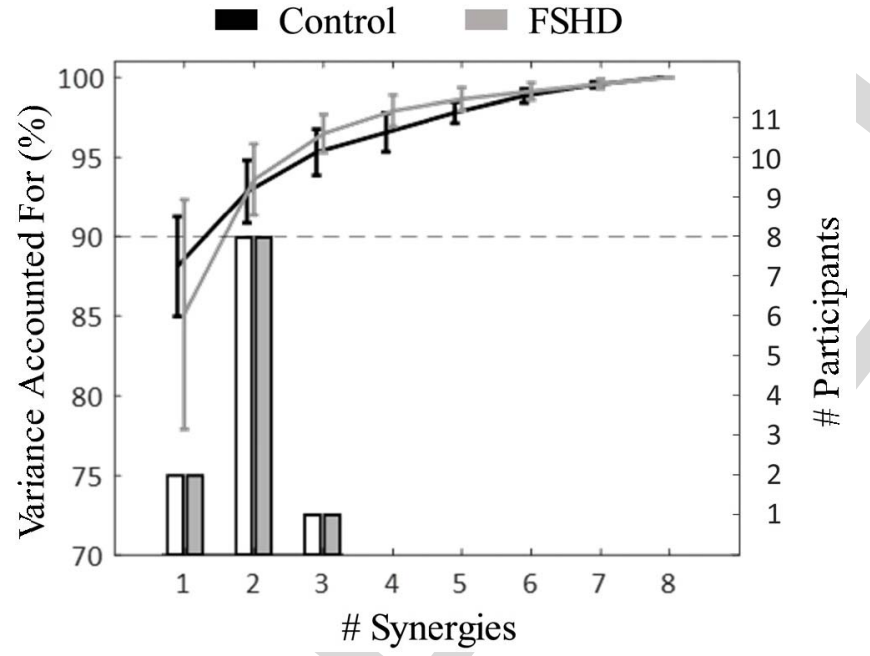

Fig. 3. Variance accounted for as means and standard deviation (lines; left $y$-axis) and number of extracted synergies (bars; right $y$-axis) of the control (black) and FSHD group (grey). The dashed line indicates the $90 \%$ VAF threshold.

$-1.45, p: 0.004)$ and SFE: $-41 \pm 6 \%(N=22$, Cohen's $d$ : $-1.95, p: 0.001)$, and Serratus Anterior SAA: $-39 \pm 4 \%$ $(N=22$, Cohen's $d:-1.72, p:$ 0.002) (Fig. 2). Within the control group there was a significant difference between tasks (SAA-SFE) for Trapezius Ascendens: $-14 \pm 14 \%$ $\left(N=22\right.$, Cohen' $\left.^{\prime} d:-0.74, p: 0.005\right)$ and Latissimus Dorsi: $-5 \pm 6 \%(N=22$, Cohen's $d:-0.25, p: 0.024)$. Within the FSHD group significant differences between tasks (SAA-SFE) were found for Biceps Brachii: $-12 \pm 15 \%$ $\left(N=22\right.$, Cohen's $\left.^{\prime} d:-0.55, p: 0.010\right)$, Trapezius
Descendens: $+21 \pm 25 \%\left(N=22\right.$, Cohen' $^{\prime} d: 0.79, p:{ }^{270}$ $0.024)$, Pectoralis Major: $-13 \pm 16 \%(N=22$, Cohen's $d$ : $-0.80, p$ : 0.010), Serratus Anterior: $-19 \pm 23 \%(N=$ 22, Cohen's $d:-0.83, p: 0.014)$, and Latissimus Dorsi: $-17 \pm 18 \%(N=22$, Cohen's $d:-0.90, p: 0.019)$. The SEMs were $1.9 \%$ and $3.3 \%$ for the control and FSHD group, respectively.

\section{Muscle Synergies}

The number of synergies extracted were equally distributed between the two groups (Fig. 3). In each group at least $90 \%$ of the variance was described with one synergy for two participants, two synergies for eight participants, and three synergies for one participant. The control and FSHD group's synergies were clustered into two sets each (Fig. 4, 5). FSHD participants were also investigated individually and compared to the clustered control synergies (Fig. 4, 5). Appendix Fig. 8 shows the participant-specific synergies.

Synergy \#1 on average accounted for $74 \pm 19 \%$ variance for FSHD participants (controls: $87 \pm 9 \%$ ) in the SAA task and $50 \pm 35 \%$ VAF (controls: $86 \pm 9 \%$ ) in the SFE task. The VAF per task by synergy \#2 was $29 \pm 12 \%$ for FSHD participants (controls: $15 \pm 3 \%$ ) in the SAA task and $59 \pm 27 \%$ (controls: $15 \pm 6 \%$ ) in the SFE task. Within-group similarities for synergy weights \#1 and \#2 were, respectively, for controls $\mathrm{R}: 0.73 \pm 0.15(N=55)$ and R: $-0.06 \pm 0.37(N=36)$, and for FSHD R:0.00 $\pm 0.42(N=55)$ and $0.08 \pm 0.56$ $(N=36)$. Correlation of synergy weights was not significant for any synergy combination between groups. On an individual level two FSHD participants (\#6, \#9) showed significant similar synergy weights where synergy \#1 correlated with control synergy \#2 ( $p: 0.023, R: 0.78$ and $p: 0.001, R$ : 


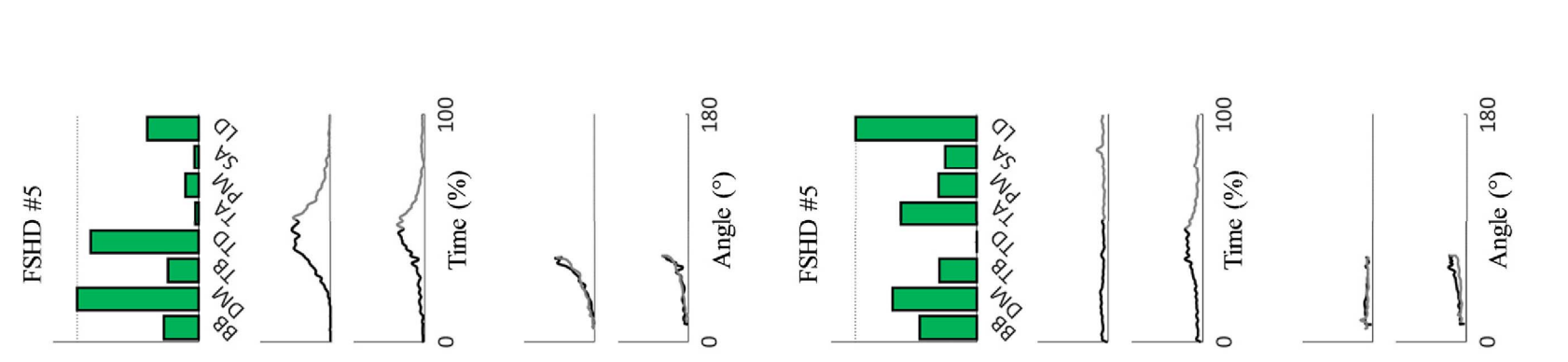

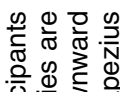

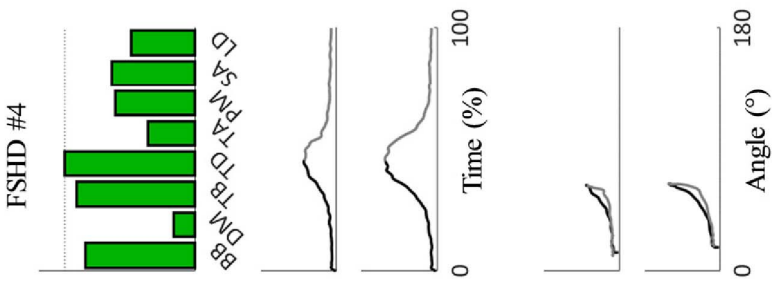

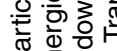

을 के

फ

正

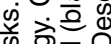

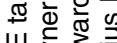

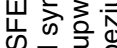

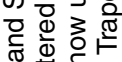

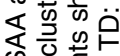

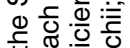

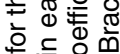

눈웡

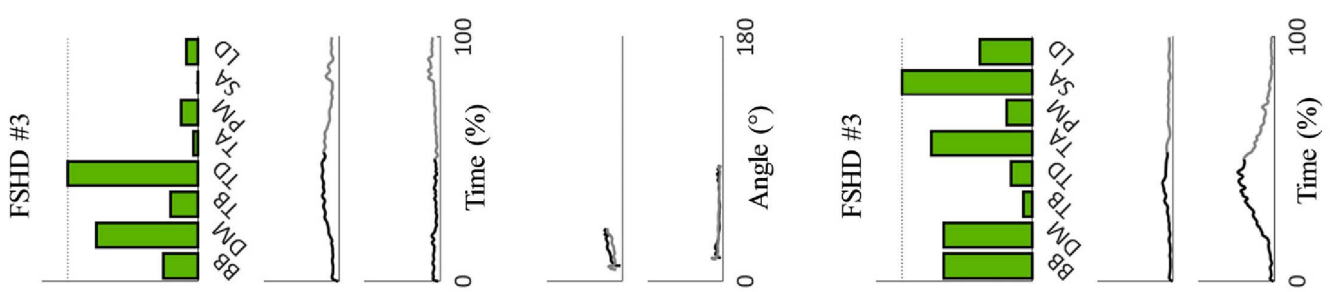

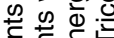

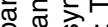

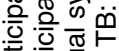

응 흥흥

응흐음

बิㄱㅎㅇ

훙ㅎㅀ

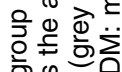

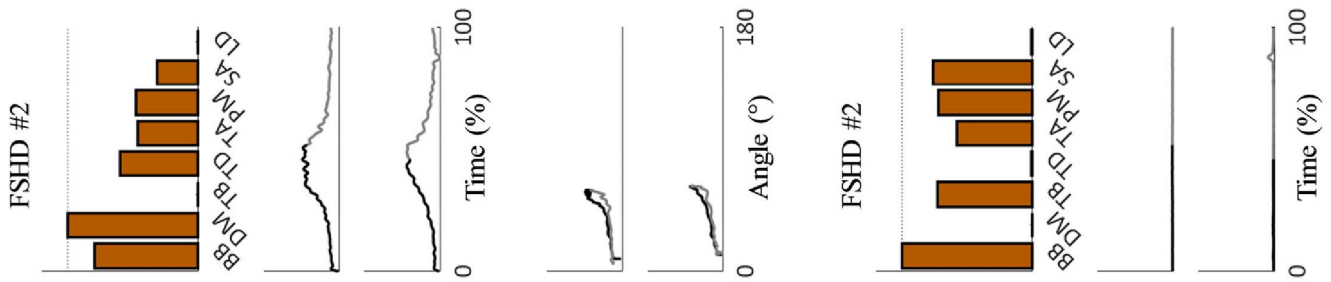

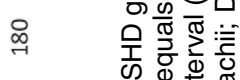

(1) $\quad$ 山 $z: \frac{\pi}{\omega}$

6

का के है

部

흘 ซํํㅇํำ

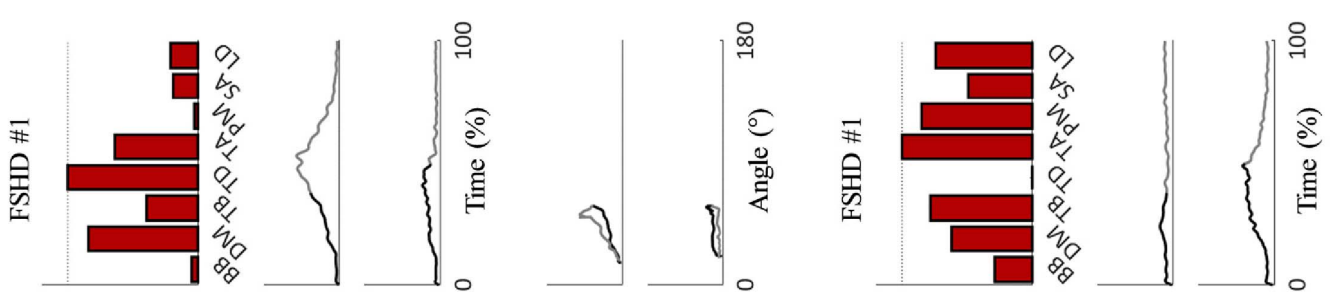

青等

흥ㅎํ

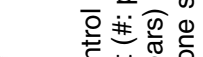

( $\quad$ 둥

递家

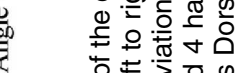

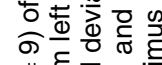

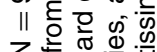

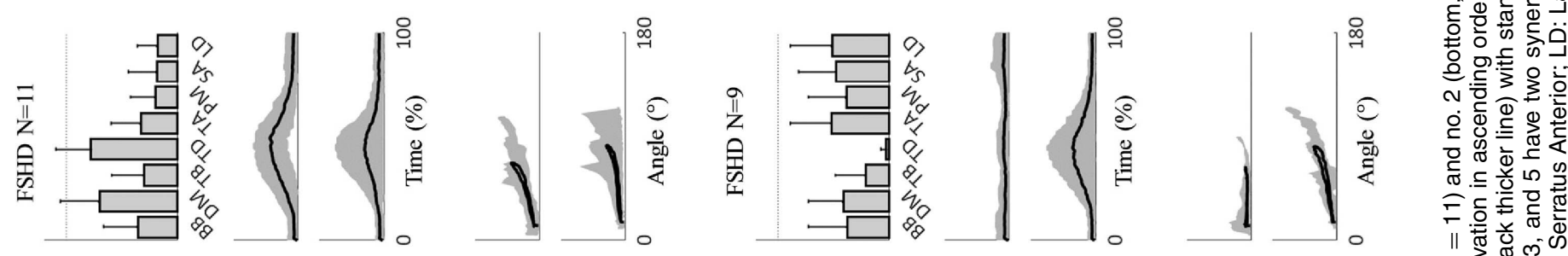

ह

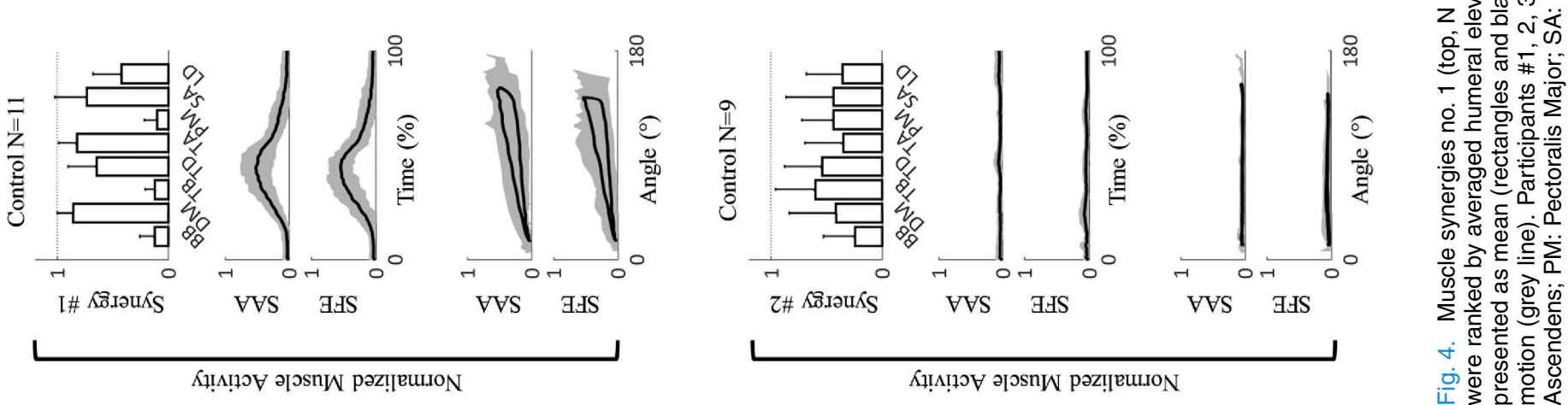




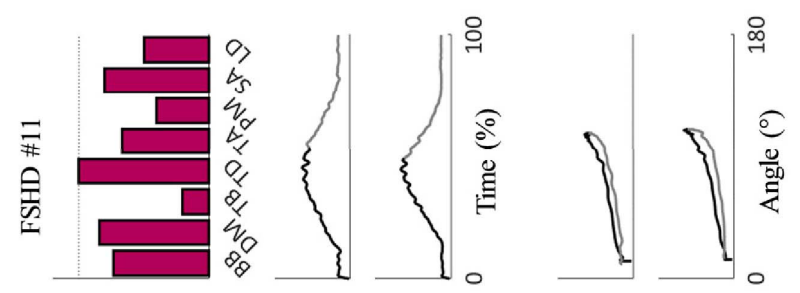

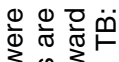

की

तั

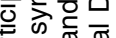

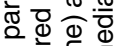

오옹

心

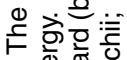

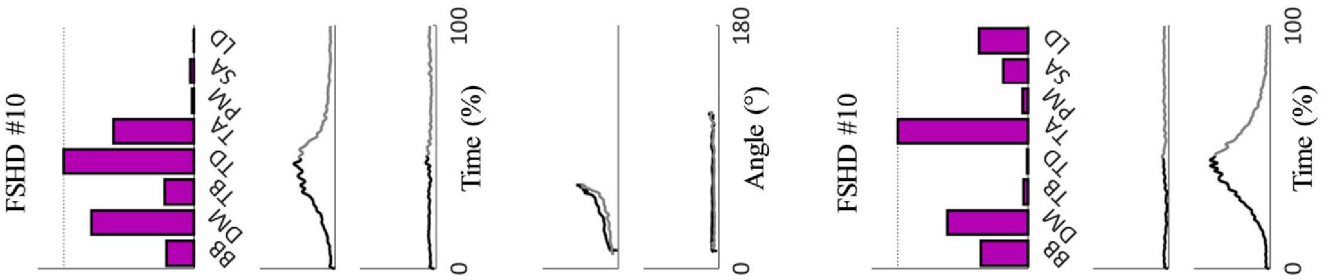

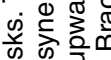

क के 응 क

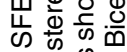

등 능

过它完

心

흘 केषे
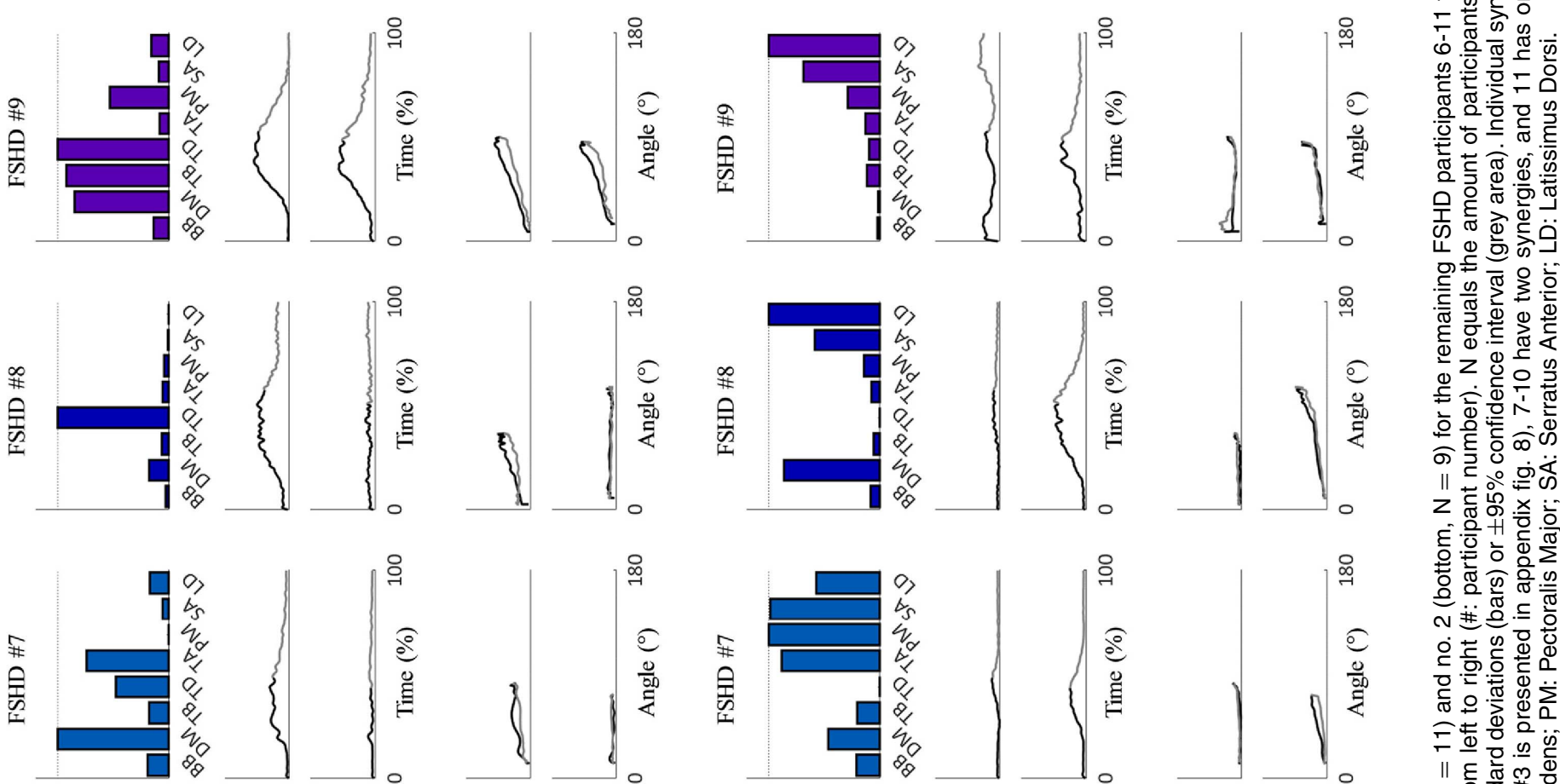

는하 흥

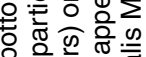

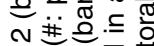

능웡웡

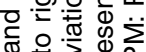

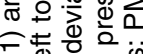

$\|$ 징 $\frac{0}{m}$

$z$ 은 풍

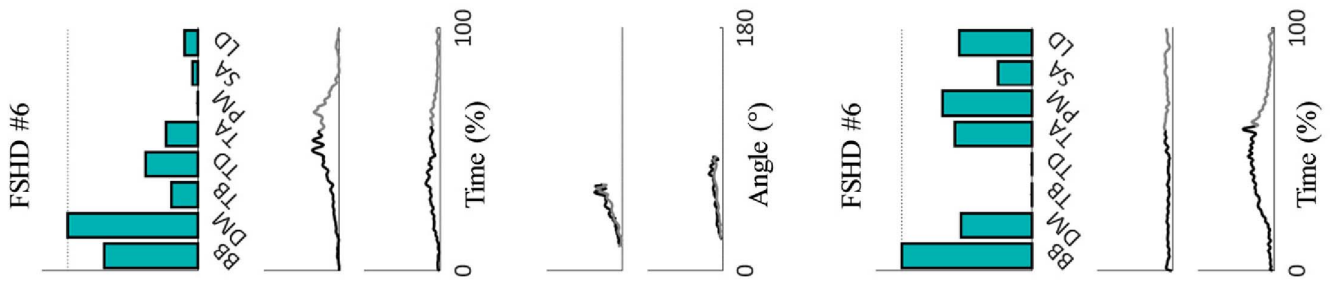

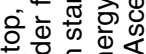

- क责市.

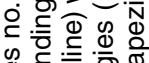

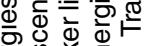

ब兯立

के व

은 $\cong \frac{0}{0} \stackrel{0}{\frac{0}{5}}$

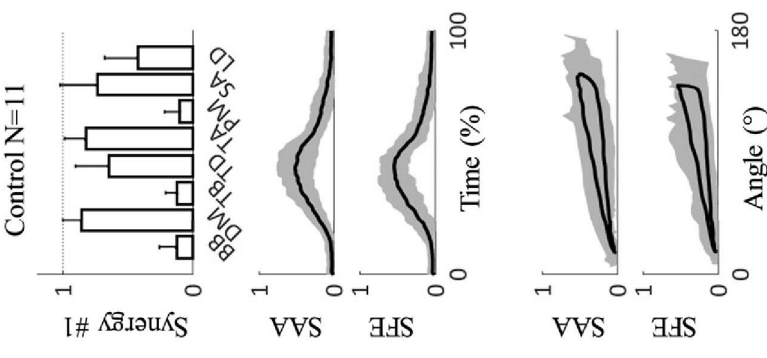

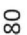
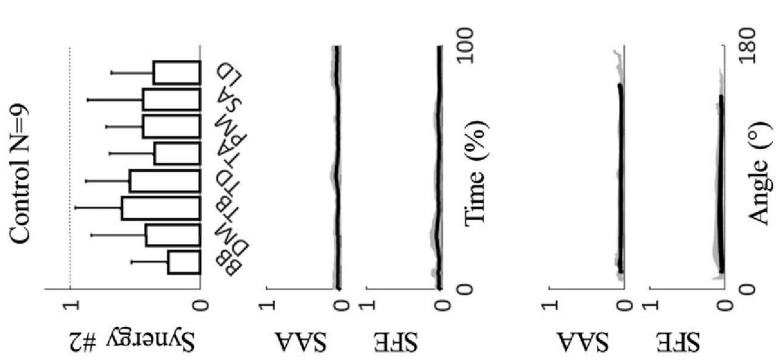

$\sum$ 음 웓

ம்

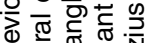

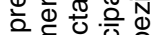

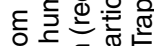

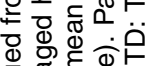

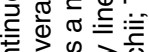

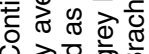

U 주휴 후 

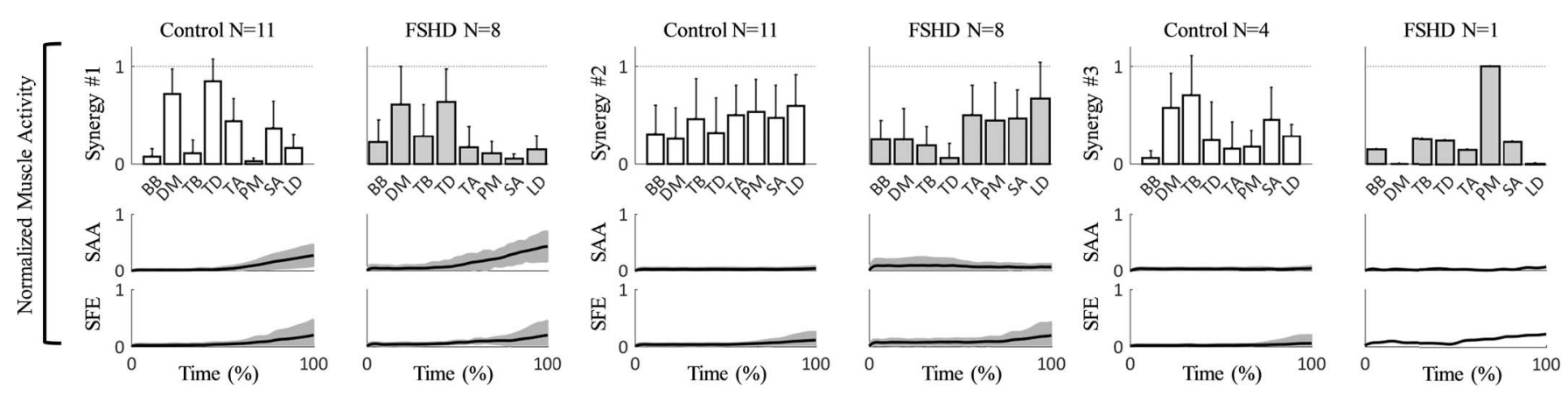

Fig. 6. Muscle synergies no. 1 (left), no. 2 (middle), and no. 3 (right) of control group (black) and FSHD group (grey) for the SAA and SFE tasks cut up to $60^{\circ}$ of humeral elevation. $\mathrm{N}$ equals the amount of participants within each clustered synergy. Clustered synergies are presented as a mean (black line) with standard deviation (bars) or $\pm 95 \%$ confidence interval (grey area). BB: Biceps Brachii; DM: medial Deltoid; TB: Triceps Brachii; TD: Trapezius Descendens; TA: Trapezius Ascendens; PM: Pectoralis Major; SA: Serratus Anterior; LD: Latissimus Dorsi.

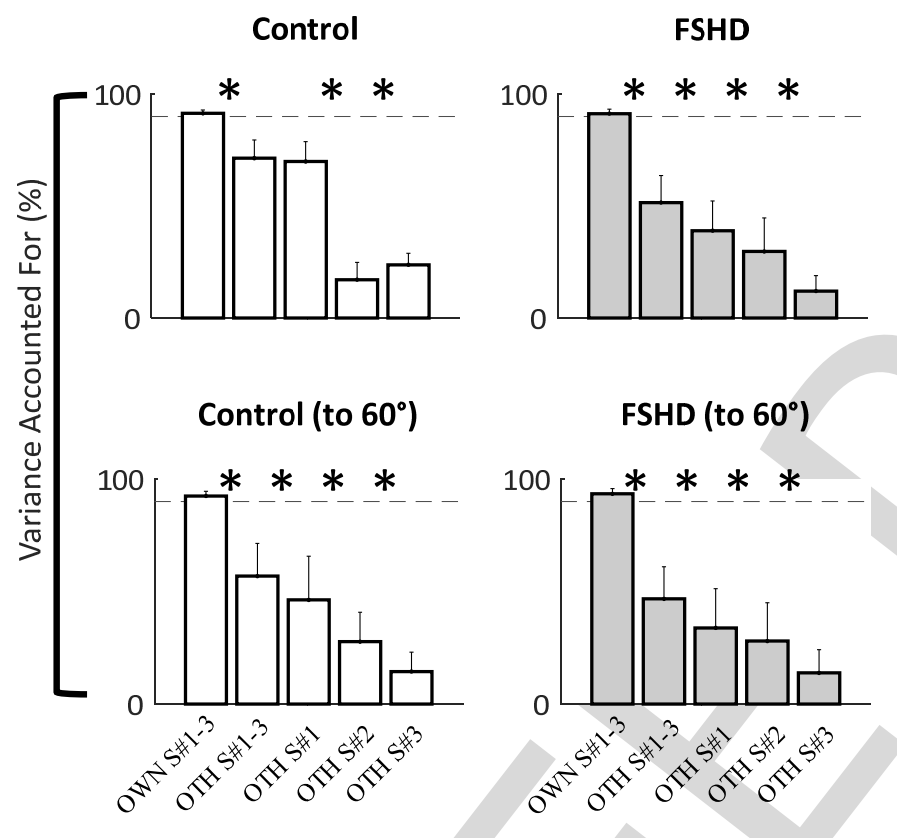

Fig. 7. Variance accounted for as means and standard deviation from EMG cross-validation performed within the control (left) and FSHD group (right) for whole motion (top) and cut to $60^{\circ}$ (bottom). Bars show calculations using participants' own synergies (OWN), and from others (OTH) for a complete synergy set (S\#1-3) and for individual synergies (S\#1, S\#2, S\#3). Dashed line indicates the $90 \%$ VAF threshold. Significant differences were indicated by*

-0.92 forparticipant\#6 and\#9, respectively). Correlation coefficients values for the SAA and SFE tasks were respectively R:0.19 and 0.24 ( FSHD\#6, $p<0.001$ and $<0.001$ ), and R:0.09 and 0.18 (FSHD\#9, $p: 0.006$ and < 0.001 ).

In the upward motion to $60^{\circ}$ humeral elevation condition, at least $90 \%$ of the variance was described by two synergies for seven controls and seven FSHD participants, and three synergies for four controls and one FSHD participant. Three FSHD participants did not reach at least $60^{\circ}$ in both tasks and were excluded for this condition. Control and FSHD participants' synergies were clustered into three sets each (Fig. 6). Synergy \#1 accounted for $63 \pm 11 \%$ variance for FSHD participants (controls: $62 \pm 17 \%$ ) in the SAA task and $39 \pm 10 \%$ (controls: $45 \pm 16 \%$ ) in the SFE task. For synergy \#2 this was $37 \pm 10 \%$ and $56 \pm 16 \%$ (controls: $29 \pm 21 \%, 47 \pm 16 \%$ ) in the SAA and
SFE tasks respectively, and $6 \%$ and $41 \%$ (controls: $24 \pm 9 \%$, $21 \pm 19 \%$ ) for synergy \#3. Synergy weights showed significant similarities between groups for synergy \#1 (R:0.84, p:0.009) where correlation coefficients values showed R:0.98 $(p<$ 0.001 ) for both tasks.

EMG cross-validations showed that less variance was accounted for by other participants' complete synergy set than one's own set in the control $(p<0.001)$ and FSHD group $(p<0.001$, fig. 7). With the exception of controls' synergy \#1, other participants' individual synergies accounted for less variance than the complete set $(p<0.001)$. Upon further inspection, synergy \#2 accounted for an additional $5 \pm 2 \% \mathrm{VAF}$ in controls after which the criteria of $>90 \%$ was met for 8 participants (Fig. 3). In the upward to $60^{\circ}$ humeral elevation condition all factors accounted for less variance than one's own synergy set $(p<0.025)$.

\section{DISCUSSION}

The activities of eight superficial shoulder muscles were studied to investigate the changes in neuromuscular output in people with FSHD during humeral elevation. We hypothesized that the maximum activities of humeral elevator, scapular rotator and synergist muscles would be increased. This was confirmed for the Biceps Brachii (SFE task only). Contrary to what was expected the activity of the scapular rotators Trapezius Ascendens and Serratus Anterior (SAA task only) significantly decreased in people with FSHD. Additionally, it was hypothesized that the muscle synergies would be altered as a result of the impaired muscle functionality. Along this line, the synergies between groups were found to differ in importance for the complete motion: within group similarity indicated that controls mostly used one synergy for both tasks while the majority of the FSHD group required two taskspecific synergies. From the comparable kinematic data and maximum muscle activities it can be concluded that while synergy weights were similar up to $60^{\circ}$ humeral elevation, the Trapezius Ascendens and Serratus Anterior contributed on average less to humeral elevation in the FSHD than in the control group. The irregularity of variances accounted for per task by each synergy and the difference in maximum muscle activities, and synergy weights and coefficients, suggest the presence of participant-specific adaptation mechanisms. 
The muscle activities of the control group for medial Deltoid (40-69\%), Serratus Anterior (60-65\%), Trapezius Ascendens (45-60\%), Trapezius Descendens (35-55\%), Latissimus Dorsi (10-23\%), and Pectoralis Major (5-20\%) during shoulder abduction-adduction or flexion-extension were consistent with other literature findings [13]-[15]. Maximum elevation angles in the control and FSHD group were also in line with a comparable study [13], while trends in increased activity of Trapezius Descendens and Pectoralis Major found by others [13] were not significant in this study. This could be ascribed to the large variability in muscle activation of people with FSHD [36], and partly to methodological differences in the MVCs protocol used for the Trapezius Descendens. In this study a strap over the shoulder was used to limit the participants' movements during the Trapezius Descendens MVCs recordings, while in [13] the participants' shoulders were manually restrained.

The activities of the lower scapular rotator muscles during humeral elevation tasks in FSHD are presented for the first time in this study. The decreased activities of Trapezius Ascendens and Serratus Anterior muscles reveal that these scapular lateral rotators generated a lower force and thus a lower moment to rotate the scapula, a movement which is necessary during humeral elevation [16]. This insufficiency was confirmed by visual observations of very limited scapular rotation in the FSHD group. The decreased activity of these muscles appears to be a characteristic signature of the FSHD disease, which is in contrast with an increased activity of Trapezius Ascendens and Serratus Anterior found in shoulder impingement and post-stroke patients [17]-[22]. Ultimately, the inability to laterally rotate the scapula leads to a decrease in humeral elevation. This situation could produce unnecessary stress on the rotator cuff muscles, which provide a stabilizing function of the glenohumeral head and are preserved in FSHD individuals, based on MRI evidence [11], [12]. The increased synergist Biceps Brachii activity likely assisted in the stabilization of the humeral head and the elevation of the humerus within the decreased range of scapular motion [37]. However, a larger variability in muscle contributions did not reveal a clear relationship between the activity of lower scapular rotators or synergist muscles and the amount of humeral elevation.

At the level of intra-task differences between SAA and SFE, a significant increased activity in the FSHD group was found for the Serratus Anterior and Pectoralis Major while an increased activity trend occurred for the Trapezius Ascendens muscle. The higher activity of the Pectoralis Major is consistent with the greater abduction moment required during forward flexion. Furthermore, more scapulothoracic internal rotation is known to occur in healthy shoulders during shoulder flexion-extension than abduction-adduction [16], while external rotation of the scapula increases following Serratus Anterior fatigue [38]. A higher activity of the Trapezius Ascendens and Serratus Anterior during shoulder flexion-extension is therefore consistent with the requirements for more internal scapula rotation and joint stability.

In order to understand whether the coordinated activity, i.e. synergy weights, of selected muscles underlines possible compensatory strategies in the FSHD group, a muscle synergy analysis was carried out and presented here for the first time in this population. The synergies accounting for the highest proportion of the VAF (Fig. 4, 5) showed a changed coordinating action of humeral elevator and scapular rotator muscles. Specifically, synergy \#1 for the control group was most likely responsible for glenohumeral elevation, scapula rotation and scapula stabilization, as exemplified by the main contributions of the Deltoid Medial, Trapezius Descendens and Ascendens, Serratus Anterior, and Latissimus Dorsi muscles. Synergy \#1 for the FSHD group showed involvement of the Deltoid Medial and Trapezius Descendens and was therefore most likely responsible for glenohumeral elevation and scapula upward rotation. Contributions from the Trapezius Ascendens, Serratus Anterior, and Latissimus Dorsi muscles appeared diminished compared to the control group, reflecting the differences found in maximum muscle activity. The controls' second synergy was characterized by low muscle activation and follows from the methodological choice of accounting for $>90 \%$ variance of all muscles. We postulate that this second synergy is a collection of short activation bursts $(<20 \%)$ from different muscles, possibly to stabilize or facilitate the movement. Eight out of eleven FSHD participants used a second synergy with distinct coefficients for the SFE task. This second synergy was most likely responsible for scapula rotation and stabilization. This synergy also differs from the first in the contributions from Trapezius Ascendens and Serratus Anterior, reflecting the task-specific differences found in maximum muscle activity. Additionally, FSHD participants who applied this second synergy had higher humeral elevation angles. Similarly to what was found for the maximum activity, no clear relationships was present between the humeral elevation angles achieved and the amount of required synergies and/or involvement of scapula rotator/stabilizer muscles. The variety in muscle synergies compositions shows evidence that muscle control is less consistent in FSHD.

The synergy coefficients of similar synergy weights correlated poorly between groups. However, considering that the similarities were computed between two synergies of a high VAF proportion (FSHD) vs. a clustered synergy of a low VAF proportion (control), it is questionable whether the comparison is representative of the change at a group level. Additionally, EMG cross-validations indicated a larger data similarity within the controls than the FSHD group, revealing a higher consistency in muscle activation in the former group. Future analysis should specifically focus on evaluation of within-group similarity of synergy weights and coefficients. In summary, coordination differences in FSHD appear to reflect the physiological changes of muscles due to the disease.

On the basis of the above findings it is evident that FSHD can lead to alterations in the coordination of muscle groups and lead to altered function and thus performance in some individuals. Muscle strengthening therapy, including scapular control, is sometimes considered part of the rehabilitation treatment for impingement and scapular winging [42]-[44]. Although scapular control therapy remains a debated topic [45], future research should explore whether this therapy could be effective in people with FSHD [36], [46]. Given the limited function of the scapular rotators it is likely that therapeutic decisions 
should be made on an individual level, after careful assessment of the muscles' coordination using a methodology similar to the one proposed in this study.

\section{A. Limitations}

Muscle synergy analysis was shown to be sensitive to detect changes in motor output with respect to internal/external factors, however the technique has its limitations. The outcomes can be influenced by the choices made in EMG processing, NNMF settings, and threshold of VAFs [39], [40], [47], [48]. For example, a lower VAF threshold would reduce the required number of synergies, possibly oversimplifying the motor output. To overcome this problem, this study uses two thresholds to ensure the variance of all muscles have been accounted for on a collective as well as a singular level [24]. In addition, the statistical approach was thorough and ensured that the limitations did not affect the conclusions.

The number of muscle synergies were inconsistent between participants and resulted in two clustered synergies of eleven and nine participants. However, this can be explained by individual characteristics, unrelated to disease effects [39], [40]. Furthermore, the total number of synergies were equal between the groups. Nonetheless, this could have resulted in the large within-group variances, specifically in muscle synergy weights, where a common coordinating activity is only evident for selected muscles [41]. The presented clustering method is suitable for simple movements as examined in this study, but arguably not when multiple synergies are needed, for example during more complex motions. Other cluster analysis methods can be used to pool synergies based on more distinct weights [27], [28] and are recommended in future research.

\section{CONCLUSION}

People with FSHD showed motor output alterations during humeral elevation, which were often movement- and participant-dependent. In general, the lower scapula rotators showed decreases in activity, with compensatory increase of a synergistic upper arm muscle. A group*muscle*task interaction effect was accompanied with increased activities of the lower scapula rotators, and synergistic chest and upper arm muscles during shoulder flexion-extension compared with abduction-adduction. The large group variances indicate that individual characteristics have a large influence on motor output. An assessment of the muscles' coordination is recommended to reveal individual synergies and to design evidence-based therapy for the management of the condition.

\section{APPENDIX}

See Fig. 8 and Table II.

\section{ACKNOWLEDGMENT}

Authors would like to thank the Netherlands Organisation for Scientific Research (Den Haag, NL) for funding the Symbionics Perspectief Program project 13523 ADAPT, and the Dutch Association for Neuromuscular Diseases (Spierziekten Nederland, Baarn, NL) for their collaboration in the inclusion process by informing their members of this study.
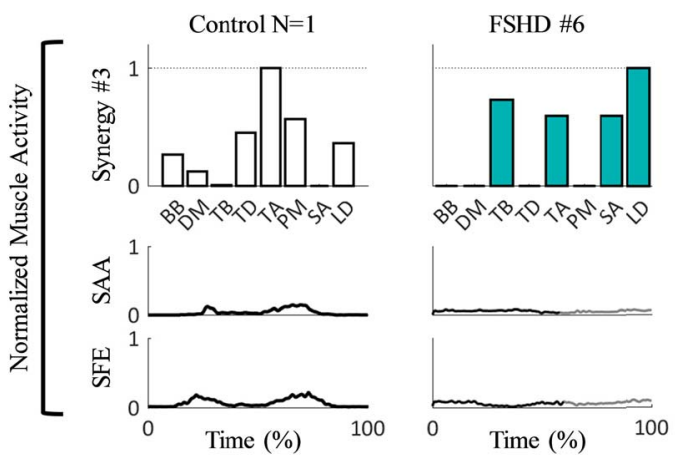

Fig. 8. Participant-specific muscle synergy of a control participant (black, 9\% VAF) and FSHD participant \#6 (dark cyan, 19\% VAF) for the SAA and SFE tasks. $\mathrm{N}$ equals the amount of participants within the clustered synergy. Individual synergy coefficients show upward (black line) and downward motion (grey line). Participant \#6 has three synergies. BB: Biceps Brachii; DM: medial Deltoid; TB: Triceps Brachii; TD: Trapezius Descendens; TA: Trapezius Ascendens; PM: Pectoralis Major; SA: Serratus Anterior; LD: Latissimus Dorsi.

\section{TABLE II}

MAXIMUM VOLUNTARY CONTRACTION PROTOCOL

\begin{tabular}{|c|c|}
\hline & Instructions \\
\hline $\begin{array}{l}\text { Biceps Brachii } \\
\text { short head } \\
\text { (BB) }\end{array}$ & $\begin{array}{l}\text { Position: Upper arm is alongside the torso. Elbow } \\
\text { is flexed at } 90^{\circ} \text { and forearm temporarily } \\
\text { supported by a researcher. A strap on the wrist } \\
\text { prevents elbow flexion. Execution: Flex the } \\
\text { elbow against the strap. }\end{array}$ \\
\hline $\begin{array}{c}\text { Medial Deltoid } \\
(D M)\end{array}$ & $\begin{array}{l}\text { Position: Upper arm is abducted at } 60^{\circ} \text {. Elbow is } \\
\text { flexed at } 90^{\circ} \text { with hand palm downwards. A strap } \\
\text { on the upper arm prevents abduction. Execution: } \\
\text { Abduct the arm against the strap. }\end{array}$ \\
\hline $\begin{array}{l}\text { Triceps Brachii } \\
\text { long head } \\
\text { (TB) }\end{array}$ & $\begin{array}{l}\text { Position: Upper arm is abducted at } 90^{\circ} \text {. Elbow is } \\
\text { flexed at } 90^{\circ} \text { with hand palm downwards. } \\
\text { Execution: Extend the forearm against the } \\
\text { resistance provided by a researcher. }\end{array}$ \\
\hline $\begin{array}{l}\text { Trapezius } \\
\text { Descendens } \\
\text { (TD) }\end{array}$ & $\begin{array}{l}\text { Position: Upper arm is alongside the torso. Elbow } \\
\text { is fully extended. A strap is placed above the } \\
\text { shoulder and medial to the acromion. Execution: } \\
\text { Pull the shoulder upwards against the strap. }\end{array}$ \\
\hline $\begin{array}{l}\text { Trapezius } \\
\text { Ascendens } \\
\quad(T A)\end{array}$ & $\begin{array}{l}\text { Position: Both upper arms are alongside the torso. } \\
\text { Elbows are fully extended. Execution: Bend the } \\
\text { trunk slightly forward and elevate the arms to } \\
\text { form a straight line from the fingertips to the hips. }\end{array}$ \\
\hline $\begin{array}{l}\text { Pectoralis Major } \\
\text { clavicular head } \\
\qquad(P M)\end{array}$ & $\begin{array}{l}\text { Position: Upper arm is abducted at } 90^{\circ} \text {. Elbow is } \\
\text { flexed at } 90^{\circ} \text { with hand palm downwards. } \\
\text { Execution: Adduct the arm to the sagittal plane } \\
\text { against the resistance provided by a researcher. }\end{array}$ \\
\hline $\begin{array}{l}\text { Serratus Anterior } \\
5-6^{\text {th }} \text { rib } \\
(S A)\end{array}$ & $\begin{array}{l}\text { Position: Upper arm is alongside the torso. Elbow } \\
\text { is fully flexed. Execution: Pull the shoulder down } \\
\text { by pushing the elbow towards the hip against the } \\
\text { resistance provided by a researcher. }\end{array}$ \\
\hline $\begin{array}{l}\text { Latissimus Dorsi } \\
\text { (LD) }\end{array}$ & $\begin{array}{l}\text { Position: Upper arm is abducted at } 90^{\circ} \text {. Elbow is } \\
\text { flexed at } 90^{\circ} \text { with hand palm downwards. } \\
\text { Execution: Adduct the upper arm against the } \\
\text { resistance provided by a researcher. }\end{array}$ \\
\hline
\end{tabular}

MVCs were executed while seated, with two repetitions and 2 minutes rest between repetitions.

\section{REFERENCES}

[1] J. C. Deenen et al., "Population-based incidence and prevalence of facioscapulohumeral dystrophy," Neurology, vol. 83, no. 12, pp. 1056-1059, Sep. 2014.

[2] J. C. Deenen et al., "The epidemiology of neuromuscular disorders: Age at onset and gender in the Netherlands," Neuromuscul. Disord., vol. 26, no. 7, pp. 447-452, Jul. 2016. 
[3] B. Janssen et al., "Distinct disease phases in muscles of facioscapulohumeral dystrophy patients identified by MR detected fat infiltration," Plos One, vol. 9, no. 1, 2014, Art. no. e85416.

[4] J. P. Stubgen and A. Stipp, "Facioscapulohumeral muscular dystrophy: A prospective study of weakness and functional impairment," J. Neurol., vol. 257, no. 9, pp. 1457-1464, Sep. 2010.

[5] J. M. Statland and R. Tawil, "Risk of functional impairment in facioscapulohumeral muscular dystrophy," Muscle Nerve, vol. 49, no. 4, pp. 520-527, Apr. 2014.

[6] A. Bergsma, E. H. Cup, M. M. Janssen, A. C. Geurts, and I. J. de Groot, "Upper limb function and activity in people with facioscapulohumeral muscular dystrophy: A web-based survey," Disab. Rehabil., vol. 39, no. 3, pp. 236-243, Feb. 2017.

[7] J. J. Han et al., "Reachable workspace and performance of upper limb (PUL) in duchenne muscular dystrophy," Muscle Nerve, vol. 53, no. 4, pp. 545-554, Apr. 2016.

[8] A. K. Meininger, B. F. Figuerres, and B. A. Goldberg, "Scapular winging: An update," J. Amer. Acad. Orthopaedic Surgeons, vol. 19, no. 8, pp. 453-463, Aug. 2011.

[9] J. J. Han, E. De Bie, A. Nicorici, R. T. Abresch, R. Bajcsy, and G. Kurillo, "Reachable workspace reflects dynamometer-measured upper extremity strength in facioscapulohumeral muscular dystrophy," Muscle Nerve, vol. 52, no. 6, pp. 948-955, Dec. 2015.

[10] J. J. Han, G. Kurillo, R. T. Abresch, E. de Bie, A. Nicorici, and R. Bajcsy, "Reachable workspace in facioscapulohumeral muscular dystrophy (FSHD) by Kinect," Muscle Nerve, vol. 51, no. 2, pp. 168-175, Feb. 2015.

[11] G. Tasca et al., "Upper girdle imaging in facioscapulohumeral muscular dystrophy," PLoS One, vol. 9, no. 6, 2014, Art. no. e100292.

[12] S. Gerevini et al., "Muscle MRI findings in facioscapulohumeral muscular dystrophy," Eur. Radiol., vol. 26, no. 3, pp. 693-705, Mar. 2016.

[13] A. Bergsma, A. Murgia, E. H. Cup, P. P. Verstegen, K. Meijer, and I. J. de Groot, "Upper extremity kinematics and muscle activation patterns in subjects with facioscapulohumeral dystrophy," Arch. Phys. Med. Rehabil., vol. 95, no. 9, pp. 1731-1741, Sep. 2014.

[14] D. Wattanaprakornkul, M. Halaki, C. Boettcher, I. Cathers, and K. A. Ginn, "A comprehensive analysis of muscle recruitment patterns during shoulder flexion: An electromyographic study," Clin. Anatomy, vol. 24, no. 5, pp. 619-626, Jul. 2011.

[15] J. Wickham, T. Pizzari, K. Stansfeld, A. Burnside, and L. Watson, "Quantifying 'normal' shoulder muscle activity during abduction," J. Electromyography Kinesiol., vol. 20, no. 2, pp. 212-222, Apr. 2010.

[16] P. M. Ludewig, V. Phadke, J. P. Braman, D. R. Hassett, C. J. Cieminski, and R. F. LaPrade, "Motion of the shoulder complex during multiplanar humeral elevation," J. Bone Joint Surg. Amer, vol. 91, no. 2, pp. 378-389, Feb. 2009.

[17] L. Pellegrino, M. Coscia, M. Muller, C. Solaro, and M. Casadio, "Evaluating upper limb impairments in multiple sclerosis by exposure to different mechanical environments," Sci. Rep., vol. 8, Feb. 2018, Art. no. 2110 .

[18] G. Prange, M. Jannink, A. Stienen, H. van der Kooij, M. IJzerman, and $\mathrm{H}$. Hermens, "An explorative, cross-sectional study into abnormal muscular coupling during reach in chronic stroke patients," J. NeuroEng. Rehabil., vol. 7, no. 1, p. 14, Dec. 2010.

[19] T. S. Huang, H. L. Ou, C. Y. Huang, and J. J. Lin, "Specific kinematics and associated muscle activation in individuals with scapular dyskinesis," J. Shoulder Elbow Surg., vol. 24, no. 8, pp. 1227-1234, Aug. 2015.

[20] J. J. Lin et al., "Altered patterns of muscle activation during performance of four functional tasks in patients with shoulder disorders: Interpretation from voluntary response index," J. Electromyography Kinesiol., vol. 16, no. 5, pp. 458-468, Oct. 2006.

[21] A. D. Lopes, M. K. Timmons, M. Grover, R. M. Ciconelli, and L. A. Michener, "Visual scapular dyskinesis: Kinematics and muscle activity alterations in patients with subacromial impingement syndrome," Arch. Phys. Med. Rehabil., vol. 96, no. 2, pp. 298-306, Feb. 2015.

[22] G. F. Moraes, C. D. Faria, and L. F. Teixeira-Salmela, "Scapular muscle recruitment patterns and isokinetic strength ratios of the shoulder rotator muscles in individuals with and without impingement syndrome," J. Shoulder Elbow Surg., vol. 17, no. 1, pp. S48-S53, Jan. 2008.

[23] N. A. Bernstein, The Co-Ordination and Regulation of Movements. New York, NY, USA: Oxford, 1967.

[24] L. H. Ting and S. A. Chvatal, "Decomposing muscle activity in motor tasks," Motor Control Theories, Experiments Applications. New York, NY, USA: Oxford Univ. Press, 2010, pp. 102-138.
[25] J. Roh, W. Rymer, and R. F. Beer, "Evidence for altered upper extremity muscle synergies in chronic stroke survivors with mild and moderate impairment," Front. Hum. Neurosci., vol. 9, p. 11, Feb. 2015.

[26] V. C. Cheung et al., "Muscle synergy patterns as physiological markers of motor cortical damage," Proc. Nat. Acad. Sci., vol. 109, no. 36, pp. 14652-14656, Jun. 2012.

[27] V. C. Cheung, L. Piron, M. Agostini, S. Silvoni, A. Turolla, and E. Bizzi, "Stability of muscle synergies for voluntary actions after cortical stroke in humans," Proc. Nat. Acad. Sci., vol. 106, no. 46, pp. 19563-19568, Nov. 2009

[28] A. Scano, A. Chiavenna, M. Malosio, L. Molinari Tosatti, and F. Molteni, "Muscle synergies-based characterization and clustering of poststroke patients in reaching movements," Front. Bioeng. Biotechnol., vol. 5, p. 62, Oct. 2017.

[29] NDI. (201). Northern Digitial Inc. [Online]. Available: https://www. ndigital.com/

[30] Delsys. (2017). Wearable Sensors for Movement Sciences. [Online]. Available: http://www.delsys.com/products/emg-auxiliarysensors/trigno-flex/

[31] J. Feys, "Nonparametric tests for the interaction in two-way factorial designs using R," $R$ J., vol. 8, no. 1, pp. 367-378, 2016.

[32] J. Cohen, Statistical Power Analysis for the Behavioral Sciences, 2nd ed. New York, NY, USA: Lawrence Erlbaum Associates, 1988.

[33] J. Weir, "Quantifying test-retest reliability using the intraclass correlation coefficient and the SEM," J. Strength Conditioning Res., vol. 19, no.1, pp. 231-240, 2005.

[34] A. Saito, A. Tomita, R. Ando, K. Watanabe, and H. Akima, "Muscle synergies are consistent across level and uphill treadmill running," Sci. Rep., vol. 8, no. 1, p. 5979, Apr. 2018.

[35] G. T. Torres-Oviedo and L. H. Ting, "Subject-specific muscle synergies in human balance control are consistent across different biomechanica contexts," J. Neurophysiol., vol. 103, no. 6, pp. 3084-3098, 2010.

[36] A. H. Bakhtiary, J. Phoenix, R. H. T. Edwards, and S. P. Frostick, "The effect of motor learning in facioscapulohumeral muscular dystrophy patients," Eur. J. Appl. Physiol., vol. 83, no. 6, pp. 551-558, Dec. 2000.

[37] D. Landin, M. Thompson, and M. Jackson, "Actions of the biceps brachii at the shoulder: A review," J. Clin. Med. Res., vol. 9, no. 8 , p. 667, Aug. 2017.

[38] J. Umehara et al., "Scapular kinematic and shoulder muscle activity alterations after serratus anterior muscle fatigue," J. Shoulder Elbow Surg., vol. 27, no. 7, pp. 1205-1213, 2018.

[39] M. van der Krogt, L. Oudenhoven, A. Buizer, A. Dallmeijer, N. Dominici, and J. Harlaar, "The effect of EMG processing choices on muscle synergies before and after BoNT-A treatment in cerebral palsy," Gait Posture, vol. 49, p. 31, Sep. 2016.

[40] B. Shuman, M. Schwartz, and K. M. Steele, "Electromyography data processing impacts muscle synergies during gait for unimpaired children and children with cerebral palsy," Front. Comput. Neurosci., vol. 11, p. 50, Jun. 2017.

[41] D. Rimini, V. Agostini, and M. Knaflitz, "Intra-subject consistency during locomotion: Similarity in shared and subject-specific muscle synergies," Front. Hum. Neurosci., vol. 11, p. 586, Dec. 2017.

[42] J. H. Weon, O. Y. Kwon, H. S. Cynn, W. H. Lee, T. H. Kim, and C. H. Yi, "Real-time visual feedback can be used to activate scapular upward rotators in people with scapular winging: An experimental study," J. Physiotherapy, vol. 57, no. 2, pp. 101-107, 2011.

[43] J. San Juan, S. Gunderson, K. Kane-Ronning, and D. Suprak, "Scapular kinematic is altered after electromyography biofeedback training," J. Biomechanics, vol. 49, no. 9, pp. 1881-1886, Jun. 2016.

[44] A. Holtermann, P. Mork, L. Andersen, H. Olsen, and K. Søgaard, "The use of EMG biofeedback for learning of selective activation of intramuscular parts within the serratus anterior muscle: A novel approach for rehabilitation of scapular muscle imbalance," J. Electromyography Kinesiol., vol. 20, no. 2, pp. 359-365, 2009.

[45] K. McQuade, J. Borstad, and A. de Oliveira, "Critical and theoretical perspective on scapular stabilization: What does it really mean, and are we on the right track?" Phys. Therapy, vol. 96, no. 8, pp. 1162-1169, Aug. 2016.

[46] B. Corrado and G. Ciardi, "Facioscapulohumeral distrophy and physiotherapy: A literary review," J. Phys. Therapy Sci., vol. 27, no. 7, pp. 2381-2385, 2015.

[47] Y. Kim, T. Bulea, and D. Damiano, "Novel methods to enhance precision and reliability in muscle synergy identification during walking," Front. Hum. Neurosci., vol. 10, p. 455, Sep. 2016.

[48] K. M. Steele, M. C. Tresch, and E. J. Perreault, "The number and choice of muscles impact the results of muscle synergy analyses," Front. Comput. Neurosci., vol. 7, p. 105, Aug. 2013. 